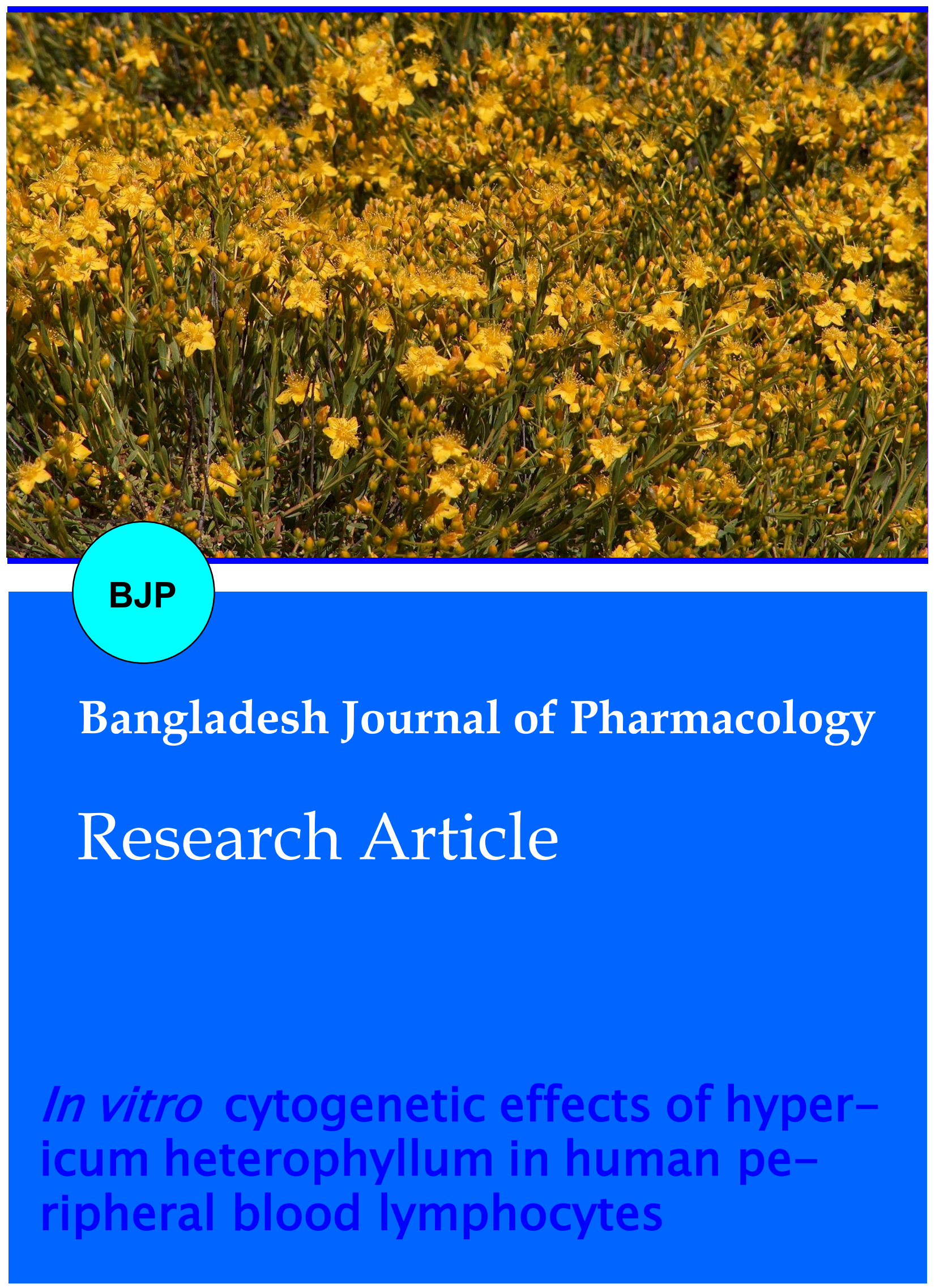


Abstracted/indexed in Academic Search Complete, Asia Journals Online, Bangladesh Journals Online, Biological Abstracts, BIOSIS Previews, CAB Abstracts, Current Abstracts, Directory of Open Access Journals, EMBASE/Excerpta Medica, Google Scholar, HINARI (WHO), International Pharmaceutical Abstracts, Open J-gate, Science Citation Index Expanded, SCOPUS and Social Sciences Citation Index;

ISSN: $1991-0088$

\title{
In vitro cytogenetic effects of Hypericum heterophyllum in human peripheral blood lymphocytes
}

\author{
Afide Öcal1 and Halil Erhan Eroğlu² \\ ${ }^{1}$ Bozok University, Science Institute, Department of Biology, Yozgat, 66200, Turkey; ${ }^{2}$ Bozok University, Faculty of \\ Science and Art, Department of Biology, Yozgat, 66200, Turkey.
}

\begin{tabular}{|c|c|}
\hline \multicolumn{2}{|l|}{ Article Info } \\
\hline & \\
\hline & \\
\hline Available Online: & \\
\hline \multicolumn{2}{|c|}{ DOI: 10.3329/bjp.v7i1.10119 } \\
\hline \multicolumn{2}{|c|}{$\begin{array}{l}\text { Cite this article: } \\
\text { Öcal A, Eroğlu HE. In vitro cytogenetic } \\
\text { effects of Hypericum heterophyllum in } \\
\text { human peripheral blood lympho- } \\
\text { cytes. Bangladesh J Pharmacol. 2012; } \\
\text { 7: } 36-41 \text {. }\end{array}$} \\
\hline
\end{tabular}

\begin{abstract}
Hypericum species have been used in traditional medicine in Turkey for thousands of years. In order to determine the cytogenetic effects of Hypericum heterophyllum, human lymphocytes were incubated with the aqueous extracts. Mitotic index frequencies and replication index values were increased with increasing extract concentrations of H. heterophyllum. The results indicate the cytotoxic effects as well as proliferative effects and suggest that the extracts of the compounds exhibit cytotoxic properties as well as mitotic and proliferative properties.
\end{abstract}

\section{Introduction}

Traditional oriental herbal prescriptions have become popular over the past decade; they are widely used for the treatment and prevention of various diseases due to their effectiveness (Shin et al., 2011).

The genus Hypericum L. (St. John's Wort, Hypericaceae) includes, at the most recent count, 484 species that are either naturally occurring on, or which have been introduced to, every continent in the world, except Antarctica. These species occur as herbs, shrubs and infrequently trees, and are found in a variety of habitats in temperate regions and in high mountains in the tropics, avoiding only zones of extreme aridity, temperature and salinity (Crockett and Robson, 2011). Hypericum heterophyllum Vent., an Endemic Turkish species, is a source of medicinal compounds and well known with its antifungal activity (Cakir et al., 2004).

The mitotic index (MI) is used to characterize the proliferating cells and to identify compounds that inhibit or induce mitotic progression (Holland et al., 2002). The MI depends on 2 factors: First the proportion of the cell population that participates in the whole cycle of interphase leading to division; second the relative lengths of interphase and recognizable mitotic stages (Walker, 1952). The replication index (RI) measures cell division kinetics by counting the percentage of cells in the first, second, and third or more metaphases (Holland et al., 2002).

Evaluation of the cytogenetic potential is one of the most important nonclinical safety studies required for registration and approval for marketing of pharmaceutical products. Furthermore, studies on the genotoxicity and cytotoxicity of medicinal plants were used by the population are needed to identify those which pose mutagenic and carcinogenic risks. In the present work, we attempted to evaluate the cytogenetic effects of $H$. heterophyllum extracts used in traditional medicine in Turkey. For this purpose, the extracts were assessed by the MI and RI on human peripheral blood lymphocytes.

\section{Materials and Methods}

\section{Preparation of the extracts}

Aqueous extracts (AE) (decoction) were prepared by 
boiling the air-dried aerial parts of the plants grounded by mechanical mill in water at $100^{\circ} \mathrm{C}$ for $5 \mathrm{~min}$ in the case of decoction. Preparations were sterilized through a filter and stored at $+4^{\circ} \mathrm{C}$.

\section{Chemicals}

PB karyotyping medium (Biological Industries, Israel), colcemid (Sigma, Germany), giemsa stain (Merck, Germany) and 5-bromo-2'- deoxyuridine (BrdU) were used in peripheral blood cultures. PB karyotyping medium is based on RPMI-1640 basal medium supplemented with L-glutamine, fetal bovine serum, antibiotics (gentamycin) and phytohemagglutinin.

\section{Human lymphocyte cultures and cell harvesting}

After getting approval from Yozgat Government Hospital, heparinized blood samples $(0.4 \mathrm{~mL})$, obtained from ten healthy donors, were placed in sterile culture tubes containing $5 \mathrm{~mL}$ of PB karyotyping medium. Then, AE were added to obtain the four final concentrations $(0.05,0.1,0.5$ and $1 \mathrm{mg} / \mathrm{mL})$. After mixing the contents of each culture tube by gently shaken, the culture tubes were incubated in a slanted position at $37^{\circ}$ $\mathrm{C}$ for 72 hours. BrdU was added for RI. After 70 hours of incubation, $0.1 \mathrm{~mL}$ colcemid solution was added to each culture tube and mixed by shaking gently. After 72 hours of incubation, the tubes were centrifuged at 2,000 rpm for $4 \mathrm{~min}$ and the supernatant was discarded. The pellet was resuspended using $10 \mathrm{~mL}$ of hypotonic solution $(0.075 \mathrm{M} \mathrm{KCl})$ and the tubes were incubated at $37^{\circ} \mathrm{C}$ for a further $4 \mathrm{~min}$. After the tubes were centrifuged at $2000 \mathrm{rpm}$ for $4 \mathrm{~min}$ and the supernatant discarded, the pellet was resuspended using $10 \mathrm{~mL}$ of fresh fixative solution (methanol:acetic acid, 3:1). The tubes were centrifuged at 2,000 rpm for $4 \mathrm{~min}$ and the supernatant was discarded. This procedure was repeated for three times. The pellet was resuspended and $0.5-1 \mathrm{~mL}$ of fresh, cold fixative solution was added to the tubes. Then 3 or 4 drops of the cell suspension were dropped on to a cold wet glass slide. Slides were air dried and were stained with 5\% Giemsa.

MI was calculated as the proportion of metaphase for 2,000 cells for each donor and concentration. RI was calculated among 500 cells per culture, according to the following formula:

$\mathrm{RI}=(1 \times \mathrm{M} 1+2 \times \mathrm{M} 2+3 \times \mathrm{M} 3) / 500$, where M1, M2 and M3 are the number of cells in first metaphase, second metaphase and third or more metaphase, respectively (Holland et al., 2002).

\section{Statistical analysis}

The computer software program SPSS 10.0 was used to analyze the data. The statistical significance of the effects of $H$. heterophyllum on the MI and RI was assessed using repeated measures of the analysis of variance (ANOVA) and the differences between groups were determined by the least significant differences (LSD) test with $\mathrm{p}<0.01$ were considered significant. Correlation and regression coefficients were calculated between two parameters (MI and doses, RI and doses, $\mathrm{MI}$ and RI, MI and age, RI and age, MI male and MI female, RI male and RI female).

\section{Results}

The peripheral lymphocytes are the best materials for the determination of cytogenetic effects. The mean values of the MI rates of added different concentrations of plant extracts were between $0.90 \pm 0.32$ and $2.44 \pm$ 0.40 (Table I). When potential genotoxicity of the extracts on lymphocyte cultures was analyzed through MI evaluation, significant increases were found at 1 $\mathrm{mg} / \mathrm{mL}(\mathrm{p}<0.01)$

RI results are parallel to MI results (Table II). Increasing extract concentrations have caused an increasing rate of RI. The changes in RI reflecting the genotoxic effects were observed at 0.5 and $1 \mathrm{mg} / \mathrm{mL}(\mathrm{p}<0.01)$. These results show that $\mathrm{MI}$ and RI values of the extracts of $H$. heterophyllum were higher than in controls. This may be attributed that many cells survived the first cell cycle in the culture, since they would have not entered a process of necrosis or apoptosis.

According to Figure 1, the strong positive correlations were observed between MI-doses ( $r=0.958)$ and RIdoses $(\mathrm{r}=0.891)$. Also, a positive correlation was observed between MI and RI ( $\mathrm{r}=0.864$; Figure 2); namely the higher or lower the MI rates were detected in exposed cells, the higher or lower the values of nuclear division progression were expressed as RI. The increases of $\mathrm{MI}$ and RI rates of the extracts of $H$. heterophyllum and the positive correlation between MI and RI could be resulted from uncontrolled cell division. MI measures the proportion of cells in the Mphase of the cell cycle and its induction could be considered as uncontrolled cell division in the cell proliferation kinetics (Eroğlu, 2008). The negative correlations were observed between $\mathrm{MI}$ and age $(\mathrm{r}=-0.674)$, RI and age ( $r=-0.537)$ (Figure 3$)$. The decrease of MI and RI with age is likely due to a combination of factors which include (i) the cumulative effect of acquired mutations in genes involved in DNA repair, chromosome segregation and cell cycle checkpoint and (ii) cytogenetic effects caused by exposure to endo- 


\section{Table I}

\section{Mitotic index (\%) in human lymphocyte cultures exposed to extracts of Hypericum heterophyllum}

\begin{tabular}{|c|c|c|c|c|c|c|}
\hline \multirow{2}{*}{$\begin{array}{l}\text { Donor } \\
\text { Gender }\end{array}$} & \multirow[b]{2}{*}{ Age } & \multicolumn{5}{|c|}{ Concentrations $(\mathrm{mg} / \mathrm{mL})$} \\
\hline & & Control & 0.05 & 0.1 & 0.5 & 1 \\
\hline Female & 18 & 2.6 & 3.2 & 3.8 & 4.6 & 5.8 \\
\hline Female & 25 & 2.1 & 2.6 & 2.6 & 2.4 & 3.4 \\
\hline Female & 30 & 2.3 & 2.9 & 3.3 & 2.8 & 3.1 \\
\hline Female & 40 & 1.8 & 3.2 & 2.4 & 3.6 & 4.5 \\
\hline Female & 50 & 1.9 & 2.4 & 2.5 & 2.2 & 2.5 \\
\hline Male & 22 & 4.0 & 4.2 & 4.0 & 5.2 & 5.2 \\
\hline Male & 27 & 2.8 & 2.7 & 2.5 & 2.3 & 2.3 \\
\hline Male & 38 & 3.5 & 3.9 & 3.8 & 4.7 & 4.9 \\
\hline Male & 56 & 2.0 & 1.6 & 1.5 & 1.7 & 3.0 \\
\hline Male & 73 & 1.1 & 1.9 & 2.0 & 2.3 & 2.3 \\
\hline MI (\%)Mean \pm SDs & & $0.9 \pm 0.3$ & $1.4 \pm 0.4$ & $1.5 \pm 0.4$ & $2.2 \pm 0.4$ & $2.4 \pm 0.4^{a}$ \\
\hline
\end{tabular}

ap $<0.01$ (significantly different from control); SDs: Standard Deviation

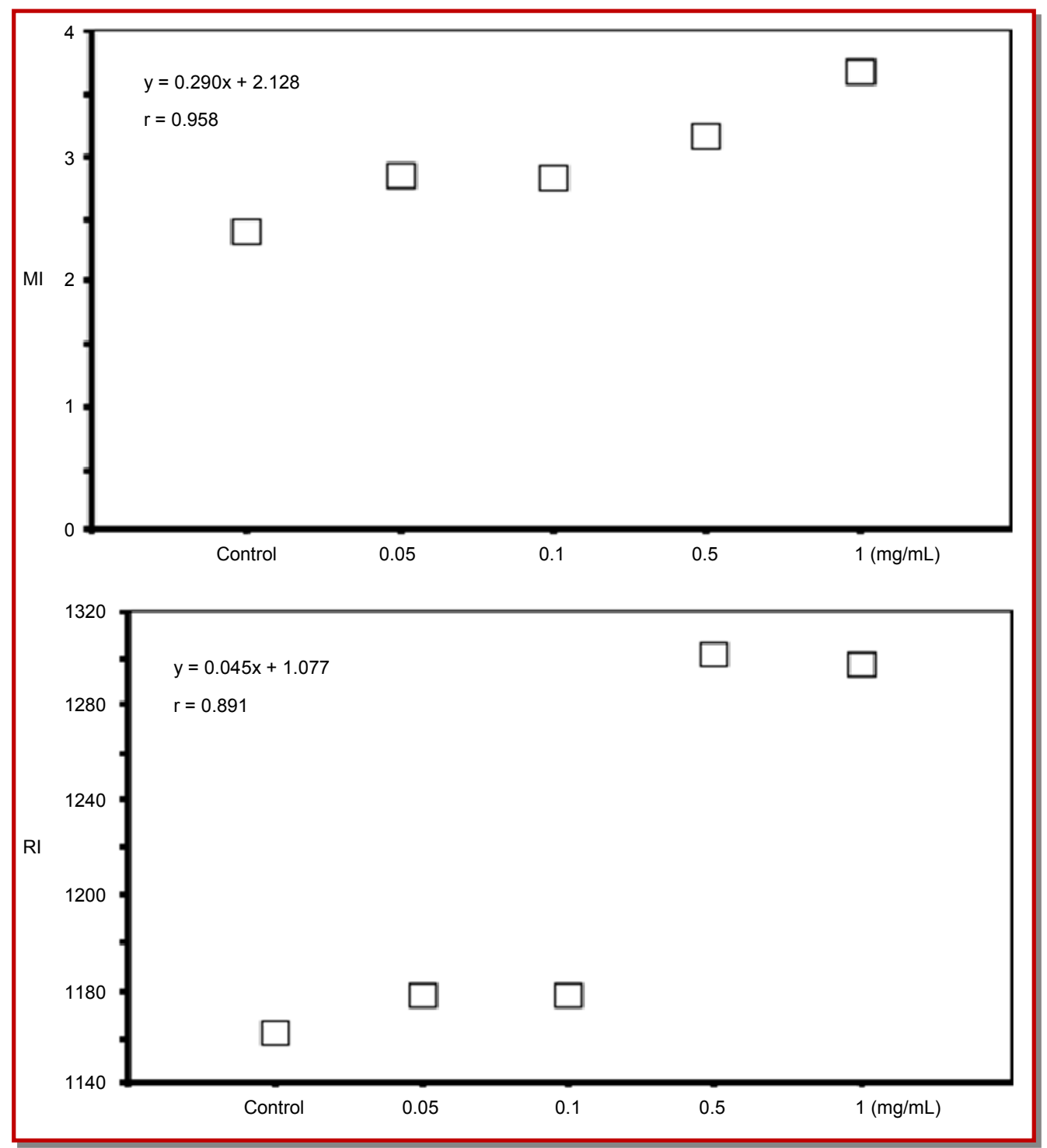

Figure 1: The positive correlations between mitotic index and the extract concentrations, replication index and the extract concentrations 


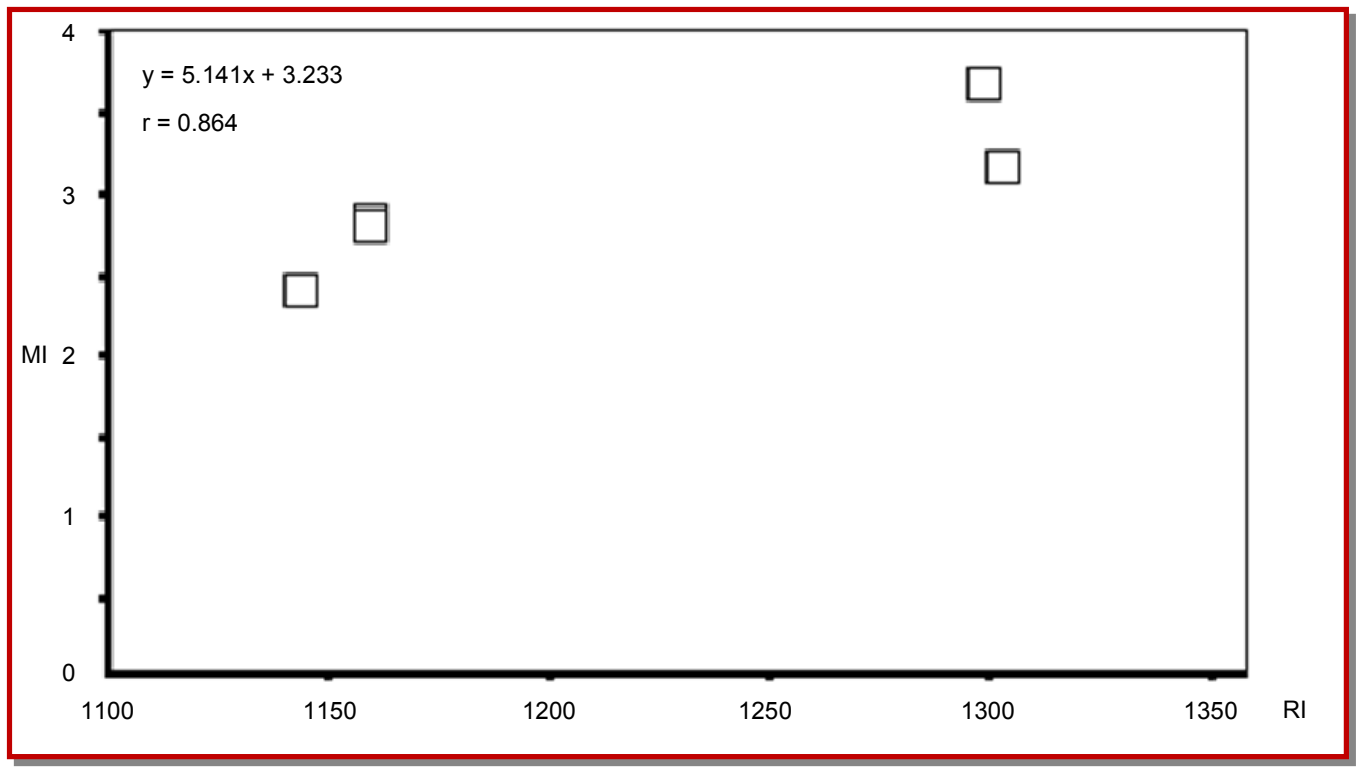

Figure 2: The positive correlation between mitotic index and replication index

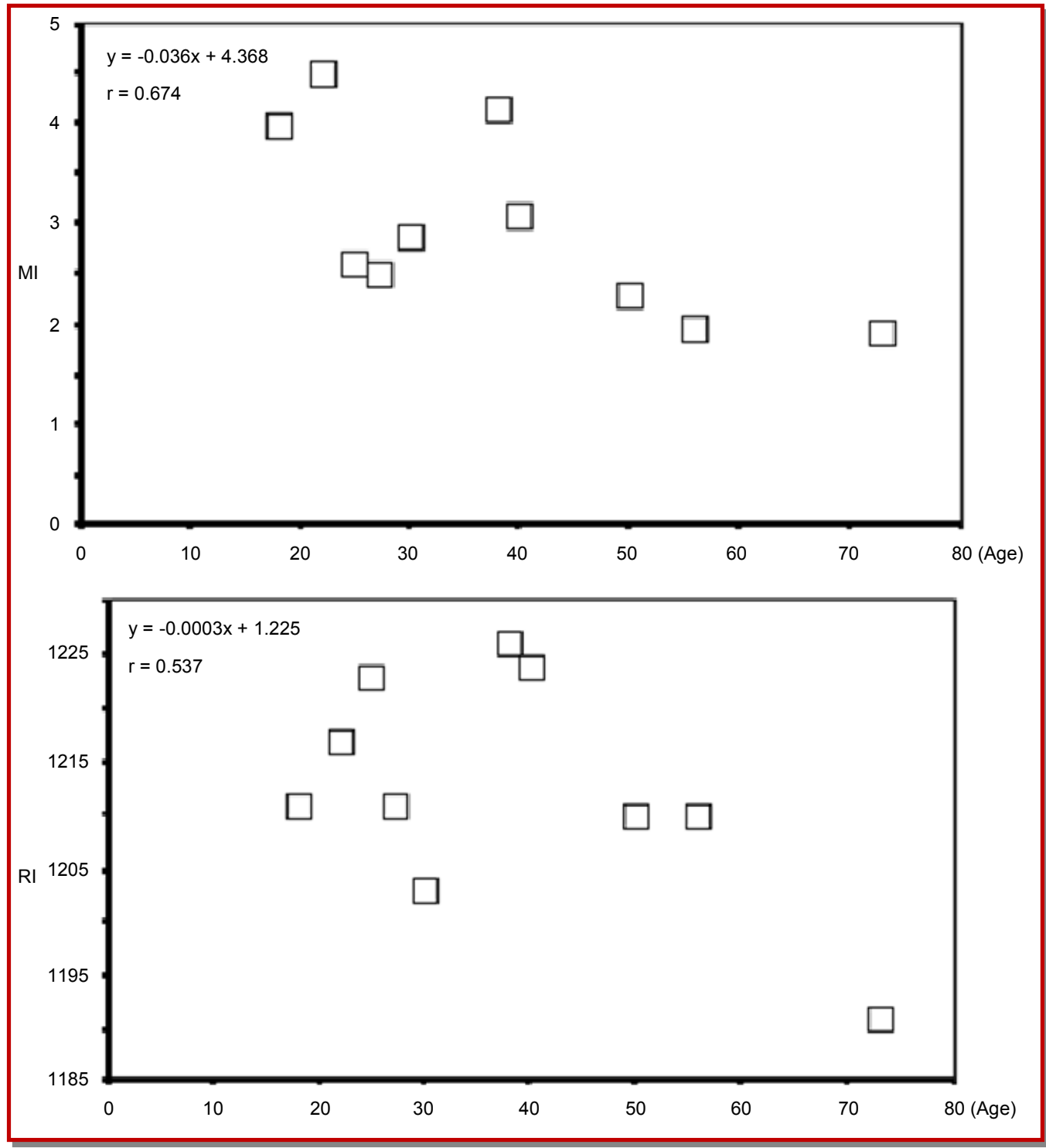

Figure 3: The negative correlations between mitotic index and age, replication index and age 


\section{Table II}

\section{Replication index in human lymphocyte cultures exposed to extracts of Hypericum heterophyllum}

\begin{tabular}{|lr|rrrrr|}
\hline Donor & \multicolumn{5}{c|}{ Concentrations $(\mathrm{mg} / \mathrm{mL})$} \\
\hline Gender & Age & Control & 0.05 & 0.1 & 0.5 & 1 \\
Female & 18 & 1.2 & 1.2 & 1.1 & 1.3 & 1.3 \\
Female & 25 & 1.1 & 1.2 & 1.2 & 1.3 & 1.3 \\
Female & 30 & 1.1 & 1.1 & 1.1 & 1.3 & 1.3 \\
Female & 40 & 1.1 & 1.2 & 1.2 & 1.3 & 1.3 \\
Female & 50 & 1.1 & 1.2 & 1.1 & 1.3 & 1.3 \\
Male & 22 & 1.1 & 1.2 & 1.2 & 1.3 & 1.3 \\
Male & 27 & 1.1 & 1.2 & 1.2 & 1.3 & 1.3 \\
Male & 38 & 1.2 & 1.2 & 1.2 & 1.3 & 1.3 \\
Male & 56 & 1.1 & 1.1 & 1.1 & 1.3 & 1.3 \\
Male & 73 & 1.1 & 1.1 & 1.1 & 1.3 & 1.3 \\
RI Mean \pm SDs & & $1.1 \pm 0.01$ & $1.1 \pm 0.01$ & $1.1 \pm 0.02$ & $1.3 \pm 0.01^{\mathrm{a}}$ & $1.3 \pm 0.01^{\mathrm{a}}$ \\
\hline
\end{tabular}

genous genotoxins, inadequate nutrition, exposure to environmental or occupational genotoxins, as well as a wide range of unhealthy lifestyle factors (Fenech and Bonassi, 2011). Pastor et al. (2001) determined an inverse negative relationship between RI and age. It was reported that a rising MI and cell proliferation will cause a more rapid decrease with increasing age, and the converse will occur with a falling index (Walker, 1952). The MI and RI rates of female were higher than male (Table I and II). The increase may result from $X$ chromosome and micronucleus frequency. Because the increase in $\mathrm{MN}$ frequency in females can be accounted for by the greater tendency of the $X$ chromosome to be lost as an MN relative to other chromosomes, and to the fact that females have two copies of the chromosome compared to only one in males (Tucker et al., 1996; Norppa and Falck, 2003).

\section{Conclusion}

The extracts of $H$. heterophyllum induced MI and RI in human lymphocytes. It can be concluded that the $H$. heterophyllum show considerable clastogenic and genotoxic effects as observed in vitro in human lymphocytes. The results indicate the cytotoxic effects as well as proliferative effects and suggest that the extracts of the compounds exhibit cytotoxic properties as well as mitotic and proliferative properties. Further studies will be needed to determine the effects of the main bioactive components isolated from this species on MI and RI.

\section{Acknowledgement}

This study was supported with research projects (I.F.E2011/49) by the Scientific Research Projects Fund of Bozok University.

\section{References}

Crockett SL, Robson NKB. Taxonomy and chemotaxonomy of the Genus Hypericum. In: Hypericum. Odabas MS, Çırak C, eds. Medicinal and Aromatic Plant Science and Biotechnology, 2011; 5: pp 1-13.

Cakir A, Kordali S, Zengin H, Izumi S, Hirata T. Composition and antifungal activity of Hypericum hyssopifolium and Hypericum heterophyllum. Flavour Frag. 2004; 19: 62-68.

Eroğlu HE. Determination of genotoxic effects of Turkey Helichrysum Mill. (Asteraceae) taxa. PhD Thesis. Erciyes University, Kayseri, Turkey, 2008.

Fenech M, Bonassi S. The effect of age, gender, diet and lifestyle on DNA damage measured using micronucleus frequency in human peripheral blood lymphocytes. Mutagenesis 2011; 26: 43-49.

Holland N, Duramad P, Rothman N, Figgs LW, Blair A, Hubbard A, Smith MT. Micronucleus frequency and proliferation in human lymphocytes after exposure to herbicide 2,4-dichlorophenoxyacetic acid in vitro and in vivo. Mutat Res. 2002; 521: 165-78.

Norppa H, Falck GC. What do human micronuclei contain?. Mutagenesis 2003; 18: 221-33. 
Pastor S, Gutiérrez S, Creus A, Cebulska-Wasilewska A, Marcos R. Micronuclei in peripheral blood lymphocytes and buccal epithelial cells of Polish farmers exposed to pesticides. Mutat Res. 2001; 495: 147-56.

Rojas E. Mitotic index and cell proliferation kinetics for the identification of antineoplastic activity. Anti-Cancer Drug. 1993; 4: 637-40.

Shin IS, Seo CS, Ha HK, Lee MY, Huang DS, Huh JI, Shin HK.
Genotoxicity assessment of Pyungwi-san (PWS), a traditional herbal prescription. J Ethnopharmacol. 2011; 133: 696-703.

Tucker JD, Nath J, Hando JC. Activation status of the X chromosome in human micronucleated lymphocytes. Hum Genet. 1996; 97: 471-75.

Walker PMB. The mitotic index and interphase processes. J Exp Biol. 1952; 31: 8-15. 